\title{
The effectiveness of vibratory stimulation in anejaculatory men with spinal cord injury. Review article
}

\author{
H Beckerman MSc PT, ${ }^{1}$ J Becher MD, ${ }^{2}$ G J Lankhorst MD ${ }^{3}$ \\ ${ }^{1}$ Research Associate, ${ }^{2}$ Physician, Rehabilitation Medicine, ${ }^{3}$ Professor of Rehabilitation \\ Medicine, Department of Rehabilitation Medicine, Free University Hospital, PO Box \\ 7057, 1007 MB Amsterdam, The Netherlands.
}

\begin{abstract}
Most spinal cord injury (SCI) men have fertility problems caused by anejaculation and a decreased fertility of the ejaculate. There are several methods to induce ejaculation, such as vibratory stimulation and transrectal electrostimulation. In order to investigate the current state of knowledge about the effectiveness of vibratory stimulation and to prepare a controlled clinical trial we reviewed the available literature. Ten articles met our inclusion criteria. Articles were found by various strategies, such as computer searches and screening of relevant journals. We used a structured approach to evaluate these articles. In total 428 patients had been treated with vibration. Sixty percent (257) of the patients responded to treatment, ie produced ejaculate. Because of methodological shortcomings in most studies it remains unclear whether there is a relationship between injury type, such as level and completeness of the injury, and the response rate. Semen analyses showed a large intersubject variation. From the data available, it could be concluded that the semen volume is usually normal, whereas sperm motility and morphology of spermatozoa were in most cases far from normal. Side effects of vibratory stimulation were reported in $6 \%$ of the patients.

Semen could be used for various (assisted) reproductive technologies, eg artificial insemination, in vitro fertilisation and microinsemination. Therefore, it is very important to know which stimulation method is most effective in treating anejaculatory SCI men. This review of the literature shows that the effectiveness of vibratory stimulation remains unclear. New, well designed clinical trials as well as basic research activities might clarify the effectiveness of vibratory stimulation and transrectal electrostimulation.
\end{abstract}

Keywords: review; vibratory stimulation; spinal cord injury; ejaculation; fertility.

\section{Introduction}

In the Netherlands, each year 400 people sustain a spinal cord injury (SCI) caused by accident. Beside other problems, most of these mainly young men are confronted with fertility problems. One of the main causes of infertility in these men concerns anejaculation, which happens to nearly $85 \%$ of them. ${ }^{1-3}$ In addition, the ejaculate has a decreased fertility. Only $13 \%$ of the SCI men have a sperm concentration of more than $20 \times 10^{6}$ spermatozoa per millimetre ejaculate. Furthermore, sperm motility lies far below the desirable level of $60 \%$. These levels are still used as criteria for normality, ${ }^{+}$ although there is evidence that the semen quality of men without a history of infertility has declined during the past 50 years. ${ }^{5}$ Factors attributed to poor quality of the ejaculate include, among other things, stasis of prostatic fluid, testicular hyperthermia, recurrent urinary tract infections and various medications, such as antibiotics. ${ }^{6}$

In recent years, several methods have been used to induce ejaculation, such as application of a vibrator to the penis, transrectal electrostimulation, direct stimulation of the hypogastric nerve, direct aspiration of sperm from the vas deferens, and other methods. Treatment of anejaculation 
and infertility is indicated if SCI men are interested in determining their fertility status or desire fathering a child.

Ejaculation consists of two separate phases. (1) The emission phase includes sperm transport from the testicles to the seminal vesicle, exudation of seminal fluid from the seminal vesicles and the prostate and closure of the bladder neck (preventing retrograde ejaculation). The sympathetic innervation (T12-L2) is responsible for the contraction of these organs and emission. (2) The ejaculation phase includes opening of the external prostatic sphincter and contraction of the smooth muscles of the urethra and the skeletal muscles of the pelvis (ischiocavernosus and bulbocavernosus), to propel the seminal fluid through the urethra. The ejaculation phase is controlled by parasympathetic and somatic nerves S2-S4. ${ }^{7}$ Depending on the level and completeness of the spinal cord injury this process is more or less impaired.

By applying a vibrator to the shaft of the penis some spinal injured men are able to ejaculate. Vibratory stimulation causes a reflex ejaculation starting with transmission of afferent nerve stimuli via the pudendal nerve from the penile shaft to nuclei in the spinal cord. Vibratory stimulation is a simple, safe, noninvasive and painless method of treatment. Furthermore, vibratory stimulation offers the distinct advantage of being adaptable for home use, without the intervention of a physician. Thus most treatment programmes start with vibration. ${ }^{8-13}$

If SCI patients fail to respond to vibration, treatment has usually been continued with transrectal electrostimulation. . $^{9.11 .13-1.5}$ There are two well described methods. namely transrectal electrostimulation as described by Brindley, ${ }^{16}$ and the method developed by Seager. ${ }^{2}$ The mechanism of both of these methods is different. Brindley stimulates the pudendal nerve, whereas Seager stimulates the pelvic muscles. At present the efficacy of each of these methods has not been studied in randomized clinical trials. In general, the treatment of infertility of SCI men is still a matter of trial and error, mainly based on clinical experience.

In preparing a randomized clinical trial (eg defining the study population, determining the sample size and duration of the recruitment period) concerning the efficacy of both methods of transrectal electrostimulation we attempted to find answers to the following questions:

1 How many spinal cord injured men can produce semen by vibrostimulation? These men possibly do not need or do not want to be treated with electrostimulation, and should therefore not be enrolled in the trial.

2 What are the characteristics of responders and nonresponders? The nonresponders can possibly be treated with electrostimulation and would be optimal candidates for the trial.

3 What is the quality of semen produced by vibrostimulation? This could be compared with the quality of semen produced by electrostimulation (eg the method of Brindley or of Seager).

In order to investigate the current state of knowledge about the effectiveness of vibratory stimulation we reviewed the available literature on this topic.

\section{Method}

\section{Literature search}

Articles were eligible if they met the following inclusion criteria:

1 Intervention: the study had to deal with vibratory stimulation.

2 Study design: controlled and uncontrolled clinical trials (eg planned experiments) were selected. In addition, unplanned observational studies were included as well as individual case reports.

3 Study population: only studies comprising men with a spinal cord injury were included.

4 Language: trials published in any language were eligible.

Articles were found by various strategies. A computer search was carried out (MEDLINE for the period 1980-1992) using the key words 'spinal cord injury', 'infertility' and 'vibration', 'vibratory stimulation' or 'vibrostimulation'. In addition, a number of 
relevant journals were screened and references in articles were examined. Finally, some articles were found by checking the proceedings of conferences.

\section{Assessment of the literature}

To obtain valid answers to our research questions we decided to use a structured approach to evaluate the literature. ${ }^{17-19}$ Table I lists the criteria we used to assess the quality of the articles selected. Inclusion of all available studies in a review, not taking into account the validity of the study, can introduce a substantial amount of information bias. The first criterion (A) concerns the description of the treatment. Different treatment techniques, number of treatments and treatment frequency could result in different outcomes. Therefore, a detailed description is necessary. The presence of inclusion and exclusion criteria in the articles (criterion B) was checked to assess the consistency of the investigator in choosing admissions to the study. Admission criteria allow the reviewer to appraise the suitability of the input and provide some of the many instructions needed to duplicate a study. Furthermore, without defining beforehand the inclusion and exclusion criteria, there is

Table 1 Criteria for assessing the literature of studies dealing with vibratory stimulation of SCI men

A Description of the treatment Method

Apparatus (frequency, amplitude)

Duration of each stimulation

Treatment frequency

B Inclusion and exclusion criteria of the study population

C Sample size

D Results of relevant outcome measures Response (antegrade, retrograde ejaculation), nonresponse

Semen volume $(\mathrm{ml})$

Sperm count $(10 \% / \mathrm{ml})$

Sperm motility ( $\%)$

Sperm motility (total count)

Morphology (\% normal)

E Characteristics of the responders and the nonresponders

F Side effects a danger of reporting only the positive results. Uncontrolled trials and unplanned observational studies especially have the potential to provide a very distorted view of the efficacy of a therapy.

The sample size of the study (criterion C) gives some idea about the relevance and the generalisation of the study results. Large sample sizes allow subgroup analyses, and possibly give better insight into patients who do or do not respond.

The main outcome parameters (criterion D) are the number of responders (with antegrade or retrograde ejaculation) and nonresponders, semen volume, sperm count, sperm motility, and morphology.

Characteristics of responders and, more importantly, nonresponders give us an idea about the study population to be included in our randomised clinical trial (criterion E). Using this information, sample size calculations and prevalence figures of SCI men in the Netherlands, the duration of the recruitment period and related to this the duration of the trial can be estimated. If a unicentre trial were to be too long, we could possibly start a multicentre trial in which the same number of patients could be recruited in a shorter period.

Beside the importance of the efficacy of a treatment, one should also be aware of adverse effects. Because vibration may have side effects leading to its nonindication, another treatment could be indicated, for instance transrectal electrostimulation. If one is aware of side effects, some could possibly be prevented; thus side effects should be reported (criterion F).

\section{Results}

Ten studies were considered for inclusion in our review. ${ }^{11.12 .15 .20-26}$ The results of the review of these studies are presented in Tables II-V. The study by Hill ${ }^{10}$ is excluded because the author did not present separate results for vibration and electroejaculation.

\section{Procedure of vibratory stimulation}

The patient is seated upright in his chair, or is placed in a supine position. ${ }^{22}$ The upright 
position turns out to be a simple physical arrangement without the danger of falling off the table when muscle spasms occur. ${ }^{23.26}$ To induce ejaculation the vibrator is applied to the penile surface, or (the lower surface of) the glans penis. A detailed description of the treatment characteristics in each study, eg apparatus, vibration frequency, amplitude, duration of each stimulation, and treatment frequency, is presented in Table II. The frequency of the vibrators ranged from 60 to $120 \mathrm{~Hz}$, whereas the amplitude of excursion ranged from 1.5 to $4.5 \mathrm{~mm}$. Per session vibration is applied continuously or with intervals (1-3 minute pauses between the stimulations).

\section{Study population}

Most authors did not use a consistent set of criteria to demarcate the people who were eligible for admission to receive vibrostimulation. Only in four studies some inclusion and exclusion criteria were formulated. Nevertheless, none of the authors described these criteria exhaustively (see Table III). In total 428 patients were treated with vibration. Patients ranged in age from 16 to 45 years, and sustained their injury 18 days to 39 years previously.

\section{Response}

Sixty percent (257) of the patients responded to treatment, ie produced ejaculate. Table IV presents the characteristics of responders and nonresponders, such as level of injury and completeness of injury. Of these 257 responders 30 men $(11.7 \%)$ ejaculated retrograde and 227 men $(88.3 \%)$ ejaculated antegrade.

\section{Semen quality}

Of 171 SCI men (66.5\% of 257 responders) results of the semen analyses such as volume, sperm count, sperm motility and morphology were presented in some way or other (Table V). The way of presenting these numbers varied with each author. So, aggregate statistical analyses could not be made. However, there is a large intersubject variation for all outcome measures.

\section{Side effects}

Most authors reported side effects of vibratory stimulation. In general, people with high level SCI are prone to autonomic dysreflexia. Manifestations of uncontrolled autonomic nervous system reactions, like headache and raised arterial blood pressure. especially during or after ejaculation, were seen. ${ }^{12.20-22.25}$ Rawicki and Hill ${ }^{11}$ and Szasz

Table II Description of the treatment characteristics of vibratory stimulation

\begin{tabular}{|c|c|c|c|c|c|}
\hline Reference $^{\mathrm{a}}$ & Apparatus & $\begin{array}{l}\text { Frequency } \\
\quad(\mathrm{Hz})\end{array}$ & $\underset{(\mathrm{mm})}{\text { Amplitude }}$ & $\begin{array}{l}\text { Maximum duration } \\
\text { of stimulation } \\
\text { (minutes) }\end{array}$ & $\begin{array}{l}\text { Treatment } \\
\text { frequency }\end{array}$ \\
\hline Beilby ${ }^{20}$ & $\begin{array}{l}\text { Modified PIFCO } 1558 \\
\text { vibratory massager }\end{array}$ & - & $2-4$ & - & $1 / 1-3$ weeks \\
\hline Beretta $^{21}$ & Le Vibrion & 100 & - & 10 & 1/week \\
\hline Brindley 22 & Ling 201 vibrator & 80 & 2.5 & 3.5 ( 4 cycles $)$ & - \\
\hline Elliot $^{23}$ & $\begin{array}{l}\text { Converted electric } \\
\text { vibrator }\end{array}$ & - & - & $<1$ & - \\
\hline François ${ }^{24}$ & - & - & - & - & $1 / 10$ days \\
\hline Rawicki11 & Modified vibrator & 80 & - & - & - \\
\hline Sarkarati ${ }^{15}$ & Ling 201 vibrator & 80 & $1.6-2.4$ & 3.5 ( $3-4$ cycles $)$ & - \\
\hline Siösteen ${ }^{12}$ & $\begin{array}{l}\text { Relax } \\
\text { Ling } 201 \text { vibrator }\end{array}$ & $\begin{array}{r}100 \\
80\end{array}$ & $\begin{array}{l}1.5 \\
2.5\end{array}$ & 3.5 ( 4 cycles $)$ & 1/week \\
\hline Sonksen 25 & & $60-100$ & $2.5-4.5$ & 5 ( 4 cycles $)$ & $\leqslant 1 /$ week \\
\hline Szasz $^{26}$ & $\begin{array}{l}\text { Converted Wahl brand } \\
\text { Model } 7\end{array}$ & 120 & 3.0 & $2-4(4-5$ cycles $)$ & - \\
\hline
\end{tabular}

${ }^{a}$ Only first author mentioned, alphabetically ordered.

$-=$ No information available in article. 
Table III Inclusion and exclusion criteria and characteristics of the study populations

\begin{tabular}{|c|c|}
\hline Reference $^{\mathrm{a}}$ & Inclusion and exclusion criteria \\
\hline Beilby ${ }^{20}$ & $\begin{array}{l}\text { Patients referred for evaluation and } \\
\text { treatment of anejaculation and infertilit }\end{array}$ \\
\hline Beretta $^{21}$ & $\begin{array}{l}\text { Patients who attended the sexual and } \\
\text { genital rehabilitation programme } \\
1 \text { no secondary neurological sequelae } \\
2 \text { empty and not irritated rectum and } \\
\text { bladder } \\
3 \text { negative urine cultures } \\
4 \text { T12, L1 and L2 myelomeres must be } \\
\text { intact }\end{array}$ \\
\hline Brindley ${ }^{22}$ & - \\
\hline Elliot ${ }^{23}$ & - \\
\hline François ${ }^{2+}$ & - \\
\hline Rawicki $^{11}$ & $\begin{array}{l}\text { Since } 1985 \text { participants of a fertility } \\
\text { enhancement programme for SCI men, } \\
\text { for the purpose of intervening to } \\
\text { improve fertility, or to give these men } \\
\text { some idea about whether it is possible } \\
\text { that they are fertile. Since } 1989 \\
\text { vibration is part of the programme }\end{array}$ \\
\hline
\end{tabular}

93 patients (30 tetraplegic, 63 paraplegic) treated between November 1980 and July 1983

Age: 39 years; time from injury 5.5 years; level of injury: C7 complete

Mean age: 25 years (range 16-46 years) level of injury: C4-S5 (complete or incomplete); 40 men wish to father a child, 10 men wanted to find out about their fertility status

Level of injury: C4-T12

Siösteen ${ }^{12} \quad$ Patients who had been injured less than 6 months previously were excluded

Sonksen ${ }^{25} \quad-$

Szasz $^{26}$

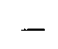

Age range: $16-36$ years; time from injury: 18 days -13 years; 11 patients had an injury less than 6 months previously; 19 complete/15 incomplete lesions

They had all wished to have their fertility potential investigated and none had been able to achieve ejaculation after injury; median age: 25 years (range 18-40 years); level of injury: C4-L1; median time from injury: 2 years (range $1-23$ years) 5 incomplete $/ 27$ complete lesions; 23 tetraplegic/9 paraplegic

Mean age: 27 years (range 18-42 years) time from injury $0.3-39$ years; level of injury: C3 incomplete-L1 complete Patients were submitted to penile vibrations with the objective of obtaining reflex ejaculation

35 SCI volunteers who wanted to find out about their fertility status; age range: $24-39$ years; time from injury range: 9 months -23 years; level of injury: $\mathrm{C} 4-\mathrm{L} 1$

${ }^{a}$ Only first author mentioned, alphabetically ordered.

- No information available in article. 
Table IV Response rate of vibratory stimulation

\begin{tabular}{|c|c|c|c|c|c|c|}
\hline Reference $^{a}$ & \multicolumn{2}{|c|}{$\begin{array}{l}\text { Characteristics of } \\
\text { patients }\end{array}$} & $\begin{array}{l}\text { Sample } \\
\text { size }\end{array}$ & Response $^{\mathrm{b}}$ & Nonresponse $^{\mathrm{b}}$ & $\begin{array}{l}\text { Percentage } \\
\text { response }\end{array}$ \\
\hline Beilby20 & $\begin{array}{l}\text { Above T1 } \\
\text { Below T1 } \\
\text { Total }\end{array}$ & & $\begin{array}{r}28 \\
9 \\
37\end{array}$ & $\begin{array}{r}19 \\
0 \\
19\end{array}$ & $\begin{array}{r}9 \\
9 \\
18\end{array}$ & 51.4 \\
\hline Beretta ${ }^{21}$ & $\begin{array}{l}\text { Cervical } \\
\text { T1-T10 } \\
\text { T11-L1 } \\
\text { L2-L5 } \\
\text { Sacral } \\
\text { Total }\end{array}$ & $\begin{array}{l}\text { complete } \\
\text { incomplete } \\
\text { complete } \\
\text { incomplete } \\
\text { complete } \\
\text { incomplete } \\
\text { complete } \\
\text { incomplete } \\
\text { complete } \\
\text { incomplete }\end{array}$ & $\begin{array}{r}7 \\
10 \\
22 \\
19 \\
10 \\
11 \\
3 \\
12 \\
3 \\
5 \\
102\end{array}$ & $\begin{array}{r}7 \\
8 \\
20 \\
15 \\
3 \\
9 \\
0 \\
7 \\
0 \\
3 \\
72\end{array}$ & $\begin{array}{r}0 \\
2 \\
2 \\
4 \\
7 \\
2 \\
3 \\
5 \\
3 \\
2 \\
30\end{array}$ & 70.5 \\
\hline $\begin{array}{l}\text { Brindley } 22 \\
<6 \text { months }\end{array}$ & \multicolumn{2}{|c|}{$\begin{array}{l}\text { Tetrapl, hip reflex }+ \\
\text { Parapl, hip reflex }+ \\
\text { Parapl, hip reflex - }\end{array}$} & $\begin{array}{l}4 \\
4 \\
4\end{array}$ & $\begin{array}{l}1 \\
0 \\
0\end{array}$ & $\begin{array}{l}3 \\
4 \\
4\end{array}$ & \\
\hline$>6$ months & $\begin{array}{l}\text { Tetrapl, } \\
\text { Parapl, hi } \\
\text { Parapl, hi } \\
\text { Total }\end{array}$ & $\begin{array}{l}\text { reflex }+ \\
\text { reflex }+ \\
\text { reflex }-\end{array}$ & $\begin{array}{l}26 \\
36 \\
19 \\
93\end{array}$ & $\begin{array}{c}22 \\
26 \\
0 \\
49^{\circ}\end{array}$ & $\begin{array}{c}4 \\
10 \\
19 \\
44^{\circ}\end{array}$ & 52.7 \\
\hline Elliot $^{23}$ & $\mathrm{C} 7$ & complete & 1 & 1 & 0 & 100.0 \\
\hline François ${ }^{24}$ & $\begin{array}{l}\mathrm{C} 4-\mathrm{C} 8 \\
\mathrm{~T} 1-\mathrm{T} 10 \\
\mathrm{~T} 11-\mathrm{L} 1 \\
\mathrm{~L} 2-\mathrm{L} 5 \\
\text { Total }\end{array}$ & $\begin{array}{l}\text { complete } \\
\text { incomplete } \\
\text { complete } \\
\text { incomplete } \\
\text { complete } \\
\text { incomplete } \\
\text { complete } \\
\text { incomplete }\end{array}$ & $\begin{array}{r}3 \\
7 \\
25 \\
4 \\
3 \\
5 \\
- \\
3 \\
50\end{array}$ & $\begin{array}{r}3 \\
6 \\
19 \\
3 \\
0 \\
4 \\
- \\
1 \\
36\end{array}$ & $\begin{array}{r}0 \\
1 \\
6 \\
1 \\
3 \\
1 \\
- \\
2 \\
14\end{array}$ & 72.0 \\
\hline Rawicki ${ }^{11}$ & $\begin{array}{l}\mathrm{C} 4-\mathrm{C} 7 \\
\mathrm{~T} 3-\mathrm{T} 8 \\
\mathrm{~T} 10-\mathrm{T} 12 \\
\text { Total }\end{array}$ & & $\begin{array}{l}3 \\
4 \\
2 \\
9\end{array}$ & $\begin{array}{l}2 \\
1 \\
1 \\
4\end{array}$ & $\begin{array}{l}1 \\
3 \\
1 \\
5\end{array}$ & 44.4 \\
\hline Sarkarati ${ }^{15}$ & $\begin{array}{l}\text { C5-C8 } \\
\text { T1-T9 } \\
\text { T10-L3 } \\
\text { Total }\end{array}$ & & $\begin{array}{c}14 \\
13 \\
7 \\
33^{d}\end{array}$ & $\begin{array}{l}4 \\
3 \\
1 \\
8^{\mathrm{c}}\end{array}$ & $\begin{array}{r}10 \\
10 \\
6 \\
25\end{array}$ & 24.2 \\
\hline Siösteen ${ }^{12}$ & Total & & $32^{\mathrm{f}}$ & 29 & 3 & 90.6 \\
\hline Sonksen ${ }^{25}$ & $\begin{array}{l}\mathrm{C} 3 \\
\mathrm{C} 4 \\
\mathrm{C} 5 \\
\mathrm{C} 5 \\
\mathrm{C} 6 \\
\mathrm{C} 6 \\
\mathrm{C} 7 \\
\mathrm{C} 7 \\
\mathrm{~T} 3 \\
\mathrm{~T} 4\end{array}$ & $\begin{array}{l}\text { incomplete } \\
\text { incomplete } \\
\text { complete } \\
\text { incomplete } \\
\text { complete } \\
\text { incomplete } \\
\text { complete } \\
\text { incomplete } \\
\text { complete } \\
\text { complete }\end{array}$ & $\begin{array}{l}2 \\
1 \\
1 \\
3 \\
2 \\
4 \\
3 \\
2 \\
1 \\
1\end{array}$ & $\begin{array}{l}1 \\
1 \\
0 \\
2 \\
2 \\
4 \\
2 \\
2 \\
1 \\
1\end{array}$ & $\begin{array}{l}1 \\
0 \\
1 \\
1 \\
0 \\
0 \\
1 \\
0 \\
0 \\
0\end{array}$ & \\
\hline
\end{tabular}


Table IV (cont)

\begin{tabular}{|c|c|c|c|c|c|c|}
\hline Reference ${ }^{a}$ & Char & $\begin{array}{l}\text { eristics of } \\
\text { tients }\end{array}$ & $\begin{array}{l}\text { Sample } \\
\text { size }\end{array}$ & Response $^{b}$ & Nonresponse ${ }^{b}$ & $\begin{array}{l}\text { Percentage } \\
\text { response }\end{array}$ \\
\hline \multicolumn{7}{|c|}{ Sonksen (cont) } \\
\hline & $\mathrm{T} 5$ & complete & 3 & 1 & 2 & \\
\hline & T6 & complete & 4 & 4 & 0 & \\
\hline & $\mathrm{T} 7$ & complete & 2 & 1 & 1 & \\
\hline & T8 & incomplete & 1 & 1 & 0 & \\
\hline & $\mathrm{T} 12$ & complete & 2 & 1 & 1 & \\
\hline & $\mathrm{T} 12$ & incomplete & 1 & 1 & 0 & \\
\hline & $\mathrm{Ll}$ & complete & 3 & 2 & 1 & \\
\hline & Total & & 36 & $27 \mathrm{~g}$ & 9 & 75.0 \\
\hline \multirow[t]{4}{*}{ Szasz ${ }^{26}$} & $\mathrm{C} 5-\mathrm{T} 4$ & & 18 & 8 & 10 & \\
\hline & $\mathrm{T} 5-\mathrm{T} 10$ & & 10 & 4 & 6 & \\
\hline & $\mathrm{T} 11-\mathrm{L} 1$ & & 7 & 0 & 7 & \\
\hline & Total & & 35 & 12 & 23 & 34.4 \\
\hline Total & & & 428 & 257 & 171 & 60.0 \\
\hline
\end{tabular}

"First author mentioned only, alphabetically ordered.

${ }^{\text {b }}$ Response is defined as antegrade or retrograde ejaculation on at least one occasion. Non-response is defined as no ejaculation at all.

'Antegrade ejaculates contain spermatozoa and/or fructose and acid phosphatase; retrograde ejaculates contain at least $5.10^{6}$ spermatozoa.

d 1 patient was not treated with vibrostimulation.

'Antegrade ejaculation.

Including 3 patients who were treated only with transrectal electrostimulation.

EEjaculation with sperm cells antegrade or retrograde.

and Carpenter ${ }^{26}$ treated autonomic dysreflexia prophylactically. Other side effects included painful contractions of abdominal muscles, superficial trauma to the glans resulting in bruising, bleeding or superficial ulceration. ${ }^{11.26}$ In total, side effects were reported in $21(5.9 \%)$ out of 357 treated patients. In three studies (with 71 treated patients) no remarks were made concerning side effects of vibratory stimulation. ${ }^{15.20 .23}$

Also of interest is the remark by Siösteen et al about two patients who dropped out because of impaired hand function, one patient because of repeated urinary infections, and one because vibration no longer resulted in ejaculations. Two others stopped after being informed about their baseline semen quality. ${ }^{12}$

\section{Discussion}

How many spinal cord injured men produced semen by vibrostimulation? Nearly $60 \%$ of 428 treated patients responded to vibration. This is confirmed by
Stien, although he did not present original trial results. ${ }^{27}$ Van Asbeck is less optimistic about vibration. ${ }^{8}$ Nevertheless, he did not present the results of his experiments either. From many studies in this review it is unclear how many attempts had been necessary to obtain semen. In some patients attempts were made on several occasions before ejaculation occurred. ${ }^{12.20,25}$ Furthermore, ejaculation could stop after the first successful vibratory stimulation. ${ }^{12}$

\section{What are the characteristics of responders and nonresponders?}

Brindley reported that the most important prognostic factor as to whether or not an ejaculate could be obtained using vibratory stimulation, was the presence or absence of reflex hip flexion on scratching the soles of the feet. Ejaculates were obtained in $75 \%$ of men with SCI who had reflex hip flexion, but in none who did not have hip flexion. ${ }^{14.22}$ This reflex indicates whether or not there is damage between L2 and S2, seg- 
Table V Semen quality of SCI men treated with vibratory stimulation

\begin{tabular}{|c|c|c|c|c|c|c|c|}
\hline Reference ${ }^{a}$ & $\begin{array}{l}\text { Sample } \\
\text { size }\end{array}$ & $\begin{array}{l}\text { Semen volume } \\
(\mathrm{ml})\end{array}$ & $\begin{array}{l}\text { Sperm count } \\
\left(10^{6} / \mathrm{ml}\right)\end{array}$ & $\begin{array}{l}\text { Total sperm } \\
\text { count }\left(10^{6}\right)\end{array}$ & $\begin{array}{l}\text { Sperm motility } \\
\qquad(\%)\end{array}$ & $\begin{array}{l}\text { Sperm motility } \\
\text { total count }\end{array}$ & $\begin{array}{l}\text { Morphology } \\
\text { (\% normal) }\end{array}$ \\
\hline Beilby ${ }^{20 b}$ & 19 & Normal & - & - & Low & - & - \\
\hline Beretta $^{21 \mathrm{c}}$ & 14 & $1.5-3.5$ & $7-90$ & - & $0-40$ & - & $15-50$ \\
\hline Brindley ${ }^{22}$ & 49 & $\begin{array}{l}\geqslant 2 n=24^{d} \\
<2 n=22\end{array}$ & - & - & - & $\begin{array}{l}\geqslant 5.10^{4} n=37 \mathrm{e} \\
<5.10^{4} n=10\end{array}$ & - \\
\hline Elliot $^{23 \mathrm{f}}$ & 1 & - & 13 & - & 10 & - & - \\
\hline François ${ }^{24}$ & 36 & $\begin{array}{rl}<1 & n=5 \\
1-3 & n=21 \\
>3 & n=10^{\mathrm{g}}\end{array}$ & $\begin{array}{rl}0 & n=5^{h} \\
<1 & n=6 \\
1-20 & n=9 \\
20-100 & n=12 \\
>100 & n=3\end{array}$ & - & $\begin{array}{rl}0 & n=7 \\
<15 & n=8 \\
16-50 & n=10 \\
>50 & n=5\end{array}$ & - & $\begin{array}{rl}<30 & n=5 \\
30-60 & n=5 \\
>60 & n=10\end{array}$ \\
\hline Rawicki11 & - & - & - & - & - & - & - \\
\hline Sarkarati 15 & 8 & $1-7$ & $7-250$ & - & $0-100$ & - & - \\
\hline Siösteen $^{12 k}$ & 16 & $2.2 \pm 0.3$ & - & - & $29 \pm 3.0$ & $192 \pm 76.10^{6}$ & $55 \pm 2.8$ \\
\hline Sonksen 251 & 16 & $0.3-3.5$ & - & $<1-584$ & $0-48$ & - & $0-84$ \\
\hline $\mathrm{Szasz}^{26 \mathrm{~m}}$ & 12 & - & $14-400$ & - & $1-40$ & - & - \\
\hline Normal values ${ }^{n}$ & & $\geqslant 2$ & $\geqslant 20$ & $\geqslant 40$ & $\geqslant 50$ & & $\geqslant 50$ \\
\hline
\end{tabular}

aOnly first author mentioned.

b99 ejaculates obtained from 125 attempts in these 19 men.

cValues after 3 months treatment: weekly vibration programme at home.

${ }^{d}$ Patients with antegrade ejaculation.

e 2 missing values.

fUnprepared sample.

$\mathrm{g} 1$ sample mixed with urine.

h1 missing value.

i1 missing value, 5 samples did not contain spermatozoa.

j16 missing values.

k Of 22 patients, 6 dropped out, values after 4-6 months treatment: weekly vibration programme at home.

IPatients with antegrade ejaculation.

mPatients with external or retrograde ejaculation.

${ }^{\mathrm{W}} \mathrm{WHO}^{4}$.

- Missing values. 
ments obviously needed for reflex ejaculation. Nevertheless, without describing inclusion and exclusion criteria it remains unclear whether a study population was randomly chosen with respect to this factor. Although none of the data predicted nonresponse with absolute certainty, Szasz and Carpenter ${ }^{26}$ suggested that absent bulbocavernosus and anal tone reflex responses (alone or together) are the most likely tests to predict nonresponse. Siösteen et al ${ }^{12}$ also suggested a relationship between the level of injury and the response rate, associating the high response rate of $91 \%$ with the fact that the majority of their study population had cervical or high thoracic lesions. Thus lower parts of the spinal cord, necessary for seminal emission, were preserved. Because of methodological shortcomings in these studies it remains unclear whether a relationship between the level of injury and the response rate exists. Future well designed clinical trials should provide definite confirmation of the suggestions made by these authors. In addition, neurophysiological studies concerning conduction velocity of the dorsal penile nerves (terminal branches of the pudendal nerve), and concerning the latency of the bulbocavernosus reflex to diagnose peripheral nerve damage, especially in men with low SCI, might help to further understand the results of these clinical trials.

For those with SCI injuries below the neurological level T5 (home) experimentation with vibratory stimulation for collection of semen appears to be safe. In men with lesions above the T5 level provocation of the autonomic dysreflexia could be prevented by medication. Thus this possible side effect is not a counterindication for vibratory stimulation.

A complicating factor in the ejaculation process of men with SCI is the possibility of retrograde ejaculation. Retrograde ejaculation may be the result of neurological or urological insufficiency. Usage of retrograde ejaculate is possible when not mixed with urine. For that purpose, the patient has to be catheterised, emptying the bladder and filling it with a special medium. After the treatment the patient, again, has to be catheterised.

\section{What is the quality of semen produced by} vibrostimulation?

Unfortunately, the semen quality was reported only for some of the responders. In addition, the description of the results is very incomplete. From the data available, it could be concluded that the semen volume seems to be normal $(\geqslant 2 \mathrm{ml}) .{ }^{4}$ On the other hand, sperm motility and the morphology of spermatozoa were in most cases far from normal.

Although there is a lack of knowledge about the relationship between treatment characteristics and semen quality, differences between the studies could be caused by differences concerning technical parameters (frequency, amplitude), duration of stimulation, site of stimulation, and treatment schedule. However, it should be noticed that these factors do not explain the large intersubject variation found in most studies.

The results from the studies of Siösteen and Beretta gave some idea about the quality that could be obtained after repeated vibratory stimulation. ${ }^{12,21}$ Thirty men, participants of a weekly vibration programme at home, were followed for 3-6 months. ${ }^{12,21}$ Only the results at the end of both trials are presented. Comparing the semen quality of the first ejaculate with the ejaculate produced after 3-6 months, both authors concluded that the semen quality improved after repeated vibrostimulation. An improvement of sperm concentration and progressive motility was evident, but the decrease of abnormal sperm morphology was especially spectacular after prolonged use of the vibrator. ${ }^{21}$ Siösteen et al ${ }^{12}$ found that total count of motile sperm, levels of fructose and acid phosphatase increased with repeated stimulations. The latter suggest improved function of the seminal vesicles and the prostate. In addition, the sperm penetration capacity of most men reached the normal level after the follow up period (penetration base $4.0 \pm 0.7 \mu \mathrm{m} / \mathrm{s}$, normal value $\geqslant 3.8 \mu \mathrm{m} / \mathrm{s}$; penetration top $9.1 \pm 0.4 \mu \mathrm{m} / \mathrm{s}$, normal value $\geqslant 9.6 \mu \mathrm{m} / \mathrm{s}){ }^{12}$

Sarkarati et al ${ }^{15}$ stated that semen obtained during the first 6 months after injury was not of a quality consistent with success- 
ful fertilisation owing to poor motility. In addition, semen quality and motility were better in patients who had been injured for more than 6 months.

Elliot et $a l^{23}$ found that retrograde ejaculate seemed to be of a better quality than antegrade ejaculate of the same person. Further investigation of the quality of retrograde ejaculate compared to antegrade ejaculate seems necessary to verify this.

\section{Conclusion}

From all these uncontrolled clinical trials and observational studies it is very difficult to obtain a reliable assessment of the effectiveness of treatment. This may explain why the success rate ranged from 24 to $100 \%$. Random selection of patients is needed in order to define the population to which the findings can be related. In many studies, especially from a hospital or clinic, this cannot be strictly followed. In this situation. scientific sampling from a well defined population is replaced with selection according to the patients' entry sequence. Nevertheless, defining the inclusion and exclusion criteria beforehand is a prerequisite for validly assessing the effectiveness of a treatment. ${ }^{19}$ Properly speaking, individual case reports should be excluded from assessing the response rate, since biological variation is such that patients with the same condition almost certainly show different responses to the given treatment. Although in general the semen is quantitatively and qualitatively subnormal, it can be used for various (assisted) reproductive technologies, like artificial insemination, in vitro fertilisation and microinsemination. ${ }^{28}$ The study by
Elliot et al $^{2.3}$ gives some idea about the quality of the semen which led to a successful pregnancy resulting from in vitro fertilisation. Furthermore, techniques selecting most viable sperm cells have been very promising and could possibly increase the chance of conception. ${ }^{29}$

In summary, by reviewing the literature it remains unclear which SCI men respond to vibratory stimulation and which men do not and should therefore be included in a trial concerning the efficacy of rectal electrostimulation. Only a new well designed clinical trial might yield more clarity about the efficacy of vibratory stimulation. In this trial, patients who do not respond to vibratory stimulation could subsequently participate in a randomised clinical trial concerning the efficacy of two methods of rectal electrostimulation. Brindley ${ }^{1+}$ as well as Sarkarati et al ${ }^{15}$ showed that it is likely that SCI men who do not respond to vibratory stimulation may still respond to rectal electrostimulation.

It is very important to know which stimulation method is most effective in treating anejaculatory SCI men. With respect to this, the comparison of vibratory stimulation with rectal electrostimulation, as well as the comparison of both methods of rectal electrostimulation with each other are of importance. Besides, basic research is needed to understand the neurophysiological mechanisms involved, and to investigate the consequences of various stimulation characteristics on the possibility of obtaining semen and on the semen quality.

Both clinical trials as well as basic research are necessary to optimise the treatment of anejaculatory men with a spinal cord injury.

\section{References}

1 Higgins GE (1979) Sexual response in spinal cord injured adults: a review of the literature. Arch Sex Behar 8(2): 173-196.

2 Bennett CJ, Seager SW, Vasher EA, McGuire EJ (1987) Sexual dysfunction and electroejaculation in men with spinal cord injury: review. J Urol 139: 453-457.

3 Otani T, Kondo A, Takita T (1985) A paraplegic fathering a child after an intrathecal injection of neostigmine: case report. Paraplegia 23: 32-37.

4 World Health Organization (1987) WHO Laboratory Manual for the Examination of Human Semen and Semen-cervical Mucus Interaction. Cambridge University Press, Cambridge.

5 Carlsen E, Giwercman A, Keiding N, Skakkebaek NE (1992) Evidence for decreasing quality of semen during the past 50 years. BMJ 305: 609-613. 
6 Linsenmeyer TA, Perkash I (1991) Infertility in men with spinal cord injury. Arch Phys Med Rehabil 72: $747-752$.

7 Kedia KR (1983) Ejaculation and emission: normal physiology, function, and therapy. In: Krane RJ, Siroky MB, Goldstein I, editors. Male Sexual Dysfunction. Little, Brown \& Co, Boston.

8 Asbeck FWA van (1992) Results with 'Seager' rectal electrostimulator in spinal cord injury patients. $J$ Rehabil Sci 5(2): 56-58.

9 Bakker H (1985) Ejaculatie bij mannen met een ruggemergletsel. Ned Tijdschr Geneeskd 129(40): $1931-1933$.

10 Hill V (1987) Let's have a baby - collection of semen. Paraplegia 25: 423-425 (abstract).

11 Rawicki HB. Hill S (1991) Semen retrieval in spinal cord injured men. Paraplegia 29: 443-446.

12 Siösteen A, Forssman L. Steen Y, Sullivan L, Wickström I (1990) Quality of semen after repeated ejaculation treatment in spinal cord injury men. Paraplegia 28: 96-104.

13 Yarkony GM (1990) Enhancement of sexual function and fertility in spinal cord injured males. Am J Phys Med Rehabil 69(2): 81-87.

14 Brindley GS (1984) The fertility of men with spinal injuries. Paraplegia 22: 337-348.

15 Sarkarati M. Rossier AB. Fam BA (1987) Experience in vibratory and electro-ejaculation techniques in spinal cord injury patients: a preliminary report. J Urol 138(1): 59-62.

16 Brindley GS (1981) Electroejaculation: its technique, neurological implications and uses. J Neurol Neurosurg Psychiatry 44: 9-18.

17 Chalmers TC, Smith H, Blackburn B, Silverman B, Schroeder B, Reitman D et al (1981) A method for assessing the quality of a randomized clinical trial. Controlled Clin Trials 2: 31-49.

18 Fowkes FGR. Fulton PM (1991) Critical appraisal of published research: introductory guidelines. BMJ 302: $1136-1140$.

19 VerVoort SM (1987) Ejaculatory stimulation in spinal cord injured men. Urology 29(3): 282-289.

20 Beilby JA. Keogh EJ (1989) Spinal cord injuries and anejaculation. Paraplegia 27: 152 (abstract).

21 Beretta G. Chelo E. Zanollo A (1989) Reproductive aspects in spinal cord injured males. Paraplegia 27: $113-118$

22 Brindley GS (1981) Reflex ejaculation under vibratory stimulation in paraplegic men. Paraplegia 19: 299-302.

23 Elliot S. Szasz G. Zouves C (1991) The combined use of vibrostimulation and in vitro fertilization: successful pregnancy outcome from a retrograde specimen obtained from a spinal cord-injured male. $J$ In Vitro Fertil Embryo Transf 8(6): 348-352.

24 François N. Lichtenberger JM. Jouannet P. Desert JF. Maury M (1980) L'éjaculation par le vibromassage chez le paraplégique à propos de 50 cas avec 7 grossesses. Annales de Médecine Physique 23(1): 24-36.

25 Sonksen JO, Drewes AM, Biering Sorensen F, Giwercman AJ (1991) [Vibration induced reflex ejaculation in patients with spinal cord injuries]. Ugeskr Laeger 153(41): 2888-2890.

26 Szasz G. Carpenter C (1989) Clinical observations in vibratory stimulation of the penis of men with spinal cord injury. Arch Sex Behav 18(6): 461-474.

27 Stien R (1992) Sexual dysfunctions in the spinal cord injured. Paraplegia 30: 54-57.

28 Rainsbury PA (1992) The treatment of male factor infertility due to sexual dysfunction. In: Brinsden PR, Rainsbury PA, editors. A Textbook of In Vitro Fertilization and Assisted Reproduction. Parthenon Publishing Group Ltd, Carnforth.

29 Rhemrev J. Jeyendran RS, Vermeiden JP. Zaneveld LJ (1989) Human sperm selection by glass wool filtration and two-layer, discontinuous Percoll gradient centrifugation. Fertil Steril 51: 685-690. 